\title{
Degradation Analysis of Thin Mg-xAg Wires Using X-ray Near-Field Holotomography
}

\author{
Sebastian Meyer ${ }^{1,+}{ }^{\oplus}$, Andreas Wolf ${ }^{1, \dagger}{ }^{\dagger}$ Daniela Sanders ${ }^{1}$, Kamila Iskhakova ${ }^{1}{ }^{\oplus}$, Hanna Ćwieka ${ }^{1}$,

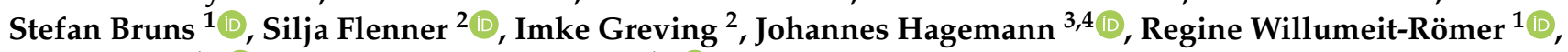 \\ Björn Wiese ${ }^{1, * \mathbb{D}}$ and Berit Zeller-Plumhoff ${ }^{1, *(\mathbb{D})}$ \\ 1 Institute of Metallic Biomaterials, Helmholtz-Zentrum Hereon, Max-Planck-Str. 1, \\ 21502 Geesthacht, Germany; sebastian.meyer@hereon.de (S.M.); andreas.wolf@hereon.de (A.W.); \\ daniela.sanders@hzg.de (D.S.); kamila.iskhakova@hereon.de (K.I.); hanna.slominska@hereon.de (H.Ć.); \\ stefan.bruns@hereon.de (S.B.); Regine.Willumeit@hereon.de (R.W.-R.) \\ 2 Institute of Materials Physics, Helmholtz-Zentrum Hereon, Max-Planck-Str. 1, 21502 Geesthacht, Germany; \\ Silja.flenner@hereon.de (S.F.); Imke.Greving@hereon.de (I.G.) \\ 3 CXNS-Center for X-ray and Nano Science, Deutsches Elektronen-Synchrotron DESY, Notkestraße 85, \\ 22607 Hamburg, Germany; johannes.hagemann@desy.de \\ 4 Helmholtz Imaging Platform, Deutsches Elektronen-Synchrotron DESY, Notkestraße 85, \\ 22607 Hamburg, Germany \\ * Correspondence: bjoern.wiese@hereon.de (B.W.); berit.zeller-plumhoff@hereon.de (B.Z.-P.) \\ + These authors contributed equally as main authors to this work.
}

\section{check for} updates

Citation: Meyer, S.; Wolf, A.; Sanders, D.; Iskhakova, K.; Ćwieka, H.; Bruns, S.; Flenner, S.; Greving, I.; Hagemann, J.; Willumeit-Römer, R.; et al. Degradation Analysis of Thin Mg-xAg Wires Using X-ray Near-Field Holotomography. Metals 2021, 11, 1422. https:// doi.org/10.3390/met11091422

Academic Editors: Ilya Okulov and Eli Aghion

Received: 21 July 2021

Accepted: 2 September 2021

Published: 8 September 2021

Publisher's Note: MDPI stays neutral with regard to jurisdictional claims in published maps and institutional affiliations.

Copyright: (c) 2020 by the authors. Licensee MDPI, Basel, Switzerland. This article is an open access article distributed under the terms and conditions of the Creative Commons Attribution (CC BY) license (https:// creativecommons.org/licenses/by/ $4.0 /)$.
Abstract: Magnesium-silver alloys are of high interest for the use as temporary bone implants due to their antibacterial properties in addition to biocompatibility and biodegradability. Thin wires in particular can be used for scaffolding, but the determination of their degradation rate and homogeneity using traditional methods is difficult. Therefore, we have employed 3D imaging using X-ray near-field holotomography with sub-micrometer resolution to study the degradation of thin (250 $\mu \mathrm{m}$ diameter) Mg-2Ag and Mg-6Ag wires. The wires were studied in two states, recrystallized and solution annealed to assess the influence of Ag content and precipitates on the degradation. Imaging was employed after degradation in Dulbecco's modified Eagle's medium and 10\% fetal bovine serum after 1 to 7 days. At 3 days of immersion the degradation rates of both alloys in both states were similar, but at 7 days higher silver content and solution annealing lead to decreased degradation rates. The opposite was observed for the pitting factor. Overall, the standard deviation of the determined parameters was high, owing to the relatively small field of view during imaging and high degradation inhomogeneity of the samples. Nevertheless, Mg-6 Ag in the solution annealed state emerges as a potential material for thin wire manufacturing for implants.

Keywords: X-ray computed tomography; magnesium-silver alloy; wire; degradation; near-field holotomography

\section{Introduction}

Magnesium $(\mathrm{Mg})$ is of high interest for the application as temporary implant material, due to its high biocompatibility and biodegradability [1]. Mg alloy implants are already in use for clinical applications in the form of bone screws or stents [2,3]. Additionally, their use as suture or splinting material is has been envisioned since the end of the 19th century [4,5]. However, the low ductility of $\mathrm{Mg}$ during bending limited its use for surgical applications [6]. The ductility of $\mathrm{Mg}$ can be improved by adapting the manufacturing technique or by alloying with appropriate elements, as summarized in the review of Alaneme and Okotete [7]. Utilizing silver (Ag) in $\mathrm{Mg}$ alloys, for example, can be used to improve the ductility [8] and additionally to add antibacterial properties [9], which is the ideal combination for an implant with high surface to volume ratio and demands for ductility during knotting. Mg wires are manufactured by hot extrusion [10] followed by 
cold drawing [5,11]. In order to achieve higher deformability of Mg wires, appropriate heat treatments and recrystallization with drawing steps are necessary. Using these techniques wire diameters close to human hair or $50 \mu \mathrm{m}$ have been produced [11].

The degradation rate of $\mathrm{Mg}$ alloys and the tailoring thereof is crucial for its use in the desired application. In $\mathrm{Mg}$ - $\mathrm{Ag}$ systems, the precipitation of $\mathrm{Ag}$ due to low temperature processing leads to an increase in the degradation rate and the homogeneity of the degradation process [9,12,13]. Similarly, higher contents of Ag have been shown to result in higher degradation rates [9,14]. By selecting the content of Ag accordingly, the degradation rate of the Mg-Ag system becomes controllable. For example, Estrin et al. [15] adjusted the degradation rate of $\mathrm{Mg}-\mathrm{Ag}$ alloys to be cytotoxic to tumour cells in in vitro tests. Processing of rolled $\mathrm{Mg}-x \mathrm{Ag}$ ( $x=6$ and $8 \mathrm{wt} . \%$ ) sheets above the solvus temperature also enabled limiting the degradation rate in physiological media to $0.5 \mathrm{~mm} /$ year after 7 days [13].

While the degradation rate of $\mathrm{Mg}$ alloys in vitro is traditionally measured using hydrogen evolution or weight loss over time [16], these methods can be imprecise when aiming to analyse the degradation of thin wires. Instead, high-resolution 3D imaging can be used to measure the volume loss, degradation rate and pitting behaviour of the material, the former of which in particular can be correlated to the material's mechanical performance [17]. High-resolution synchrotron radiation-based X-ray micro computed tomography $(\mathrm{SR} \mu \mathrm{CT})$ has previously been used to analyse the degradation behaviour of $\mathrm{Mg}$ implants, both in vitro and ex vivo [18]. However, at early degradation times, the degradation may not yet be visible in $\mathrm{SR} \mu \mathrm{CT}$ [19], which is limited in resolution to approx. $1 \mu \mathrm{m}$. Therefore, higher resolution $\mathrm{X}$-ray imaging techniques, such as transmission X-ray microscopy (TXM) and near-field holotomography (NFHT) should be utilized. For example, TXM was previously used to analyse the porosity of the degradation layer of pure $\mathrm{Mg}$ degraded in simulated body fluid at resolutions down to $40 \mathrm{~nm}$ [20]. However, TXM is still limited to field of views (FOVs) of less than $100 \mu \mathrm{m}$. NFHT is capable of achieving similar resolutions [21], while at the same time enabling a flexible selection of the size of the FOV. This is due to NFHT being a coherent propagation-based phase contrast imaging technique that employs a divergent beam [22].

In this work, we are presenting an analysis of the degradation of thin $\mathrm{Mg}-x \mathrm{Ag}(x=2$ and $6 \mathrm{wt} . \%)$ wires at early immersion time points using NFHT. By studying two processing states, specifically recrystallized vs. solution annealed, we aim to assess the influence of Ag content and precipitates on the degradation process.

\section{Materials and Methods}

\subsection{Magnesium Wires}

Pure Mg (99.98\%, MAGONTEC, Sydney, Australia) was melted under protective atmosphere of Ar with 3 vol. $\% \mathrm{SF}_{6}$. Billets with 2 and $6 \mathrm{wt} . \% \mathrm{Ag}$ (99.99\%, ESG EdelmetallService GmbH \& Co. KG, Rheinstetten, Germany) content were cast by using a modified permanent direct chill casting technique and homogenized for $8 \mathrm{~h}$ at $500{ }^{\circ} \mathrm{C}$ prior to extrusion to ensure solid solution [8]. Four wires with diameter $(\varnothing)$ of $1 \mathrm{~mm}$ were extruded from those billets with an extrusion ratio of $1: 625$ at $400{ }^{\circ} \mathrm{C}$ and a ram speed of up to $0.2 \mathrm{~mm} / \mathrm{s}$ [10]. Cold drawing followed with an area reduction of $\approx 20 \%$ per pass and a drawing speed of $0.25 \mathrm{~m} / \mathrm{s}$. After an initial steel drawing die, the 15 following dies had diamond cones to reduce iron contamination. The drawn wire was recrystallized after each pass at $425^{\circ} \mathrm{C}$ for $5 \mathrm{~min}$ to recover ductility while ensure solid solution. After the last drawing step to $0.2 \mathrm{~mm}$, the wire coil was recrystallised below $400{ }^{\circ} \mathrm{C}$ to form precipitates. One part of the samples was solid solution heat treated at $450^{\circ} \mathrm{C}$ for $2 \mathrm{~h}$. The chemical composition of the cast billets from which the wires were produced is shown in Table 1. 
Table 1. Chemical compositions of all alloys analysed with atomic absorption spectroscopy for Ag and spark emission spectroscopy for $\mathrm{Fe}, \mathrm{Cu}$, and $\mathrm{Ni}$, balance $\mathrm{Mg}$, data from [8].

\begin{tabular}{ccccc}
\hline Alloy & Ag (wt.\%) & Fe (wt.\%) & Ni (wt.\%) & Cu (wt.\%) \\
\hline Mg-2Ag & $1.97( \pm 0.06)$ & $0.0027( \pm 0.0006)$ & $0.004( \pm 0.002)$ & $0.0013( \pm 0.005)$ \\
Mg-6Ag & $5.99( \pm 0.20)$ & $0.0016( \pm 0.0002)$ & $<0.0002$ & $0.0004( \pm 0.001)$ \\
\hline
\end{tabular}

The metallographic preparation consisted of careful grinding and polishing of embedded longitudinal wire pieces. The specimens were grinding with up to 2500 grit $\mathrm{SiC}$ paper at a speed of 80 rotations $/ \mathrm{min}$. Polishing was done with a mixture of diamond paste $(1 \mu \mathrm{m})$ and O.P.S $(<0.05 \mu \mathrm{m})$ (Oxide-Polishing-Suspension, Schmitz-Metallographie $\mathrm{GmbH}$, Germany) hydrous suspension were used with at a speed of $80 \mathrm{r} / \mathrm{min}$. Picric acid solution was used as etching agent [23]. The grain size was determined by linear intercept method with the average of at least three light microscope images (BX53M, Olympus, Japan). Twin boundaries were not considered. The scanning electron microscope (SEM) (TESCAN VEGA3-SB, Brno, Czech Republic) was used in the back scattered electron (BSE) mode to visualise $\mathrm{Ag}$ distribution and precipitation with $15 \mathrm{keV}$ and a working distance of $15 \mathrm{~mm}$.

\subsection{In Vitro Degradation}

Wire pieces of $\mathrm{Mg}-2 \mathrm{Ag}$ and $\mathrm{Mg}-6 \mathrm{Ag}$ in both processing states were punched out with a $\mathrm{Mg}$ tool, to obtain reproducible sheared wire ends without Fe contamination and a length of $8 \mathrm{~mm}$.The pieces were then cleaned by sonication for $20 \mathrm{~min}$ in n-hexane, acetone, and undiluted ethanol and sterilized in 70\% ethanol (all chemicals were purchased from Sigma-Aldrich Chemie $\mathrm{GmbH}$, Munich, Germany). The degradation assays consisted of a single wire piece per well in a 96 well plate. Per well $0.3 \mathrm{~mL}$ of Dulbecco's Modified Eagle Medium (DMEM; Life technologies, Darmstadt, Germany) supplemented with $10 \%$ fetal bovine serum (FBS; Fisher Scientific $\mathrm{GmbH}$, Schwerte, Germany) was used. The samples were incubated under physiological conditions $\left(5 \% \mathrm{CO}_{2}, 20 \% \mathrm{O}_{2}, 95 \%\right.$ humidity, $\left.37^{\circ} \mathrm{C}\right)$ for $1,2,3$, and 7 days. The immersion medium was exchanged every two days.

\subsection{Near-Field Holotomography}

For mounting of the samples, polyether ether ketone pins were manufactured with a pointed tip. A $300 \mathrm{~mm}$ hole was drilled into the centre of the tip of the pins, into which the wires were inserted and fixed using blue light-curable X-ray transparent cementum. Imaging was performed at the nanotomography end-station of the P05 beamline at PETRA III, Deutsches Elektronensynchrotron (DESY), Hamburg, which is operated by HelmholtzZentrum Hereon. An X-ray energy of $11 \mathrm{keV}$ was selected using a Si-111 double crystal monochomator, with a $\triangle \mathrm{E} / \mathrm{E}$ of $10^{-4}$. A Fresnel zone plate (FZP) was used for the focussing of the beam as descripted in [24]. Order sorting apertures (OSA) were placed at the focal distance of $133 \mathrm{~mm}$ from the FZP to block its higher orders. NFHT was performed using two defocus distances, i.e., distances between the sample and the focus, which were set to 386 and $388 \mathrm{~mm}$. The focus-to-detector distance was set to $19.661 \mathrm{~m}$. The field of view was approximately $360 \mu \mathrm{m}$. Sample rotation was performed continuously over $180^{\circ}$ with an exposure time of $1.5 \mathrm{~s}$ and a speed of $0.055^{\circ} \cdot \mathrm{s}^{-1}$. Overall, imaging of one specimen required approximately $2 \mathrm{~h}$. Phase retrieval was performed using an iterative projection algorithm [25]. The tomographic reconstruction was subsequently performed using a TomoPy pipeline [26]. The resulting voxel size of the reconstructed tomogram was $175.88 \mathrm{~nm}$ in all directions. As the effective focal size is $95 \mathrm{~nm}$ [24], the magnification limits the spatial resolution in this case.

Table 2 displays an overview of the number of performed tomographic scans per $\mathrm{Mg}$ alloy, treatment and degradation time. Due to the long imaging times, the study focused on imaging wires after 3 and 7 days of degradation and only few wires of early and initial time points could be imaged for comparison. For 7 days of immersion, three 
of the obtained tomograms of each alloy and treatment were taken from the same wire to assess the degradation homogeneity per wire.

Table 2. Number of obtained tomograms per alloy, treatment, and degradation time.

\begin{tabular}{ccccc}
\hline $\begin{array}{c}\text { Degradation } \\
\text { Time (Days) }\end{array}$ & $\begin{array}{c}\text { Mg-2Ag } \\
\text { Recrystallized }\end{array}$ & $\begin{array}{c}\text { Mg-2Ag sol. } \\
\text { Annealed }\end{array}$ & $\begin{array}{c}\text { Mg-6Ag } \\
\text { Recrystallized }\end{array}$ & $\begin{array}{c}\text { Mg-6Ag sol. } \\
\text { Annealed }\end{array}$ \\
\hline 0 & - & 1 & - & 1 \\
1 & - & - & 1 & - \\
2 & - & - & 2 & - \\
3 & 4 & 3 & 3 & 4 \\
7 & 4 & 5 & 6 & 6 \\
\hline
\end{tabular}

\subsection{Image Processing and Analysis}

Initially, the reconstructed tomograms were binned by a factor of two to facilitate the segmentation. Using the watershed tool in Avizo 2020.2 (FEI SAS, Thermo Scientific, Bordeaux, France) the samples were then segmented into residual metal and background. The degradation layer was segmented as background. Any incorrectly identified regions were subsequently corrected manually. To ensure that the quantitative degradation parameters are calculated correctly, the segmented wires were registered to a perfect cylinder whose long axis coincided with the image $\mathrm{z}$-direction. The registered segmented images were then loaded into Matlab R2020a (The Mathworks Inc., Natick, MA, USA) for a quantitative analysis. Based on the segmented metal volume of a non-degraded sample $V_{0}$ with surface $A_{0}$ and the residual metal volume of a degraded sample $V_{t}$ at time $t$, the degradation rate $D R$ of the degraded sample was calculated as:

$$
D R=\frac{V_{0}-V_{t}}{A_{0} t},
$$

with dimensions scaled to $\mathrm{mm}$ /year.

Additionally, the registered segmentation was radially resliced using Fiji/ImageJ [27] with an angular step size of $0.5^{\circ}$ to enable the calculation of the pitting factor $p f$. This calculation was performed in Matlab according to:

$$
p f=\frac{\max \left(r_{0}-r_{\phi}\right)}{\operatorname{mean}\left(r_{0}-r_{\phi}\right)}
$$

with $r_{0}$ the mean radius of a non-degraded wire and $r_{\phi}$ the radius of the degraded wire at angular step $\phi \in\{0 ; 360\}$. The radii were determined in the radially resliced volume by calculating the mean maximum voxel position in the radial direction for all angles and across the height of the specimen. Finally, Matlab was used to create plots and calculate correlations of the quantitative degradation parameters.

\section{Results and Discussion}

\subsection{Material Analysis}

The recrystallisation and solution heat treatment were selected to achieve different states in the Mg-Ag wires. Figure 1 shows SEM BSE images of the cross section of the wires with Ag concentrations of 2 and $6 \mathrm{wt} . \%$ respectively after recrystallisation and after solid solution annealing. Only in the case of the wire with $6 \mathrm{wt} . \% \mathrm{Ag}$ in the recrystallised state, precipitates can be determined. They appear as bright areas in the SEM BSE micrographs separated from the $\mathrm{Mg}$ matrix. In all three other states a homogeneous distribution of elements were detected. The binary phase diagram of $\mathrm{Mg}$ and $\mathrm{Ag}$ simulated by Pandat ${ }^{\mathrm{TM}}$ 2017 with PanMagnesium 2017 thermodynamic database states full solubility of $2 \mathrm{wt} . \%$ above $380{ }^{\circ} \mathrm{C}$ and of $6 \mathrm{wt} . \%$ above $420^{\circ} \mathrm{C}$, with $\mathrm{Mg}_{4} \mathrm{Ag}$ as stable phase in equilibrium at lower temperatures $[13,28]$. This is in agreement with the microstructures in Figure 1 $(\mathrm{a}, \mathrm{b})$ and shows that the two heat treatments of $\mathrm{Mg}-2 \mathrm{Ag}$ always result in a supersaturated 
$\mathrm{Mg}$ solid solution without precipitates. The annealing temperature was $400{ }^{\circ} \mathrm{C}$, so $420{ }^{\circ} \mathrm{C}$ was not exceeded and precipitates were not dissolved completely. In this state the phase $\mathrm{Mg} 4 \mathrm{Ag}$ precipitates are thermodynamically stable in the phase diagram (Figure 1c). After the solution heat treatment, no more precipitates were detected here as well (Figure 1d). In other studies, precipitates of the stoichiometry $\mathrm{Mg}_{54} \mathrm{Ag}_{17}$ have been reported in extruded and rolled material $[9,13]$. In as cast material, Ag rich precipitates were found distributed along the grain boundaries in a regular pattern. However, the SEM BSE analysis in Figure 1 shows precipitations in a finer distributions and not limited to grain boundaries.

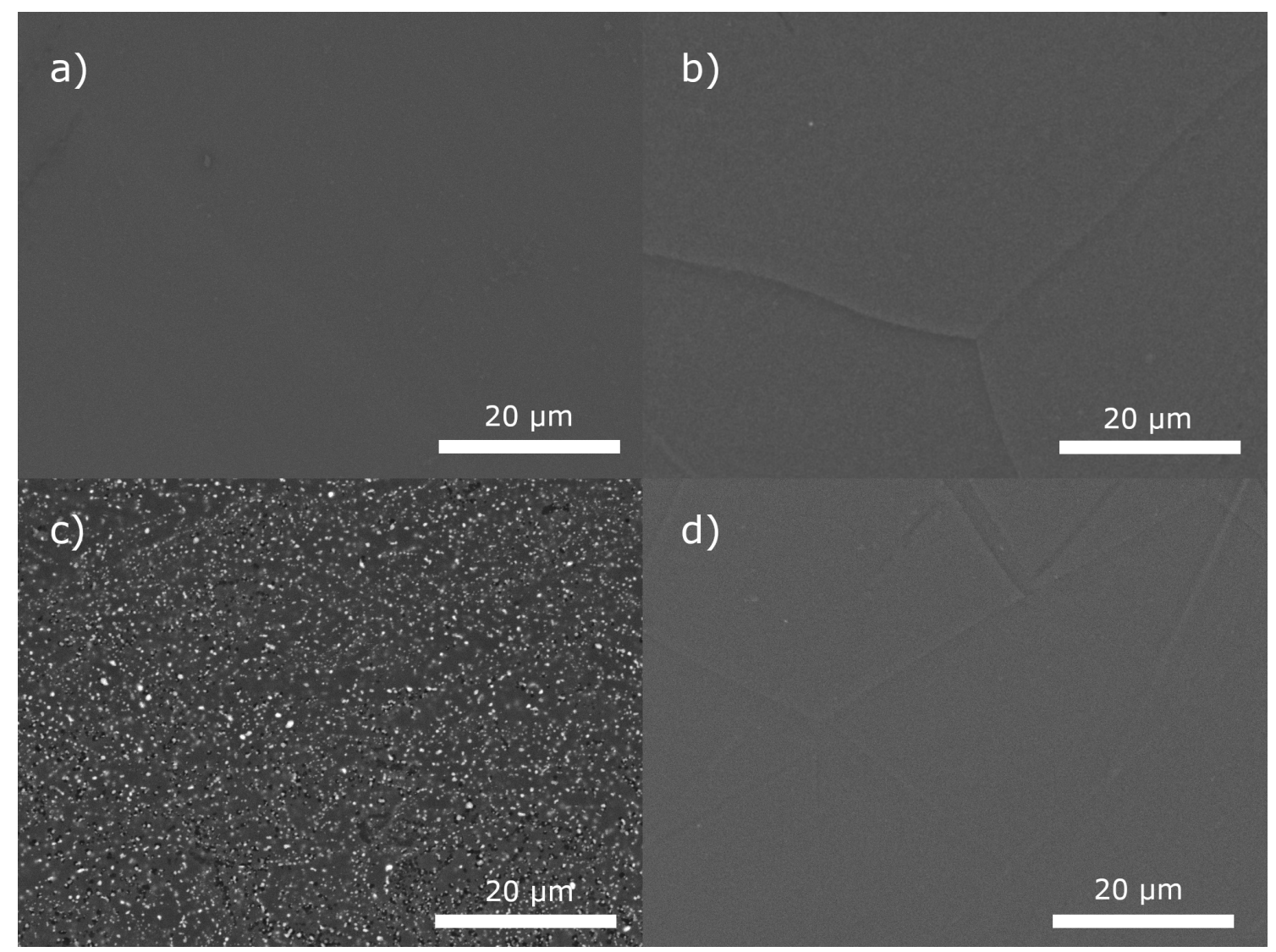

Figure 1. SEM BSE images of the wire cross section of (a) Mg-2Ag recrystallized, (b) $\mathrm{Mg}-2 \mathrm{Ag}$ sol. annealed, (c) $\mathrm{Mg}-6 \mathrm{Ag}$ recrystallized, and (d) Mg-6Ag sol. annealed.

Along with the annealing treatment and solution of the Ag precipitates, the grain size is affected and can be seen in Figure 2. The grain size was analysed using light microscopy on polished and etched cross sections of the wire and presented in Table 3 . The cold drawn wire contains many crystallographic defects in the grains. These defects act as nuclei for new grains during recrystallisation. The new grains grow into defect rich neighbouring grains to minimize the overall energy. The grain size remains around $10 \mu \mathrm{m}$ in the recrystallisation treatment but growth accelerates during the solution annealing step. Despite the inhomogeneous grain size, no abnormal grain growth is visible after annealing. Increased Ag content shows more rapid grain growth and highest grain size after sol. annealing. Bian et al. reported a grain refinement and homogenisation of the microstructure with less abnormal grain growth as Ag content increases after solution annealing [28]. From this the authors hypothesized that the segregated solute Ag effectively reduces grain boundary mobility via solute drag effects. Our results do not support this hypothesis. A direct comparison may not be permissible as grain growth in the wire is limited and influenced by its diameter. For the samples in this study it rather supports the statement that no pronounced segregation or accumulation of Ag at grain boundaries occur throughout all samples. 


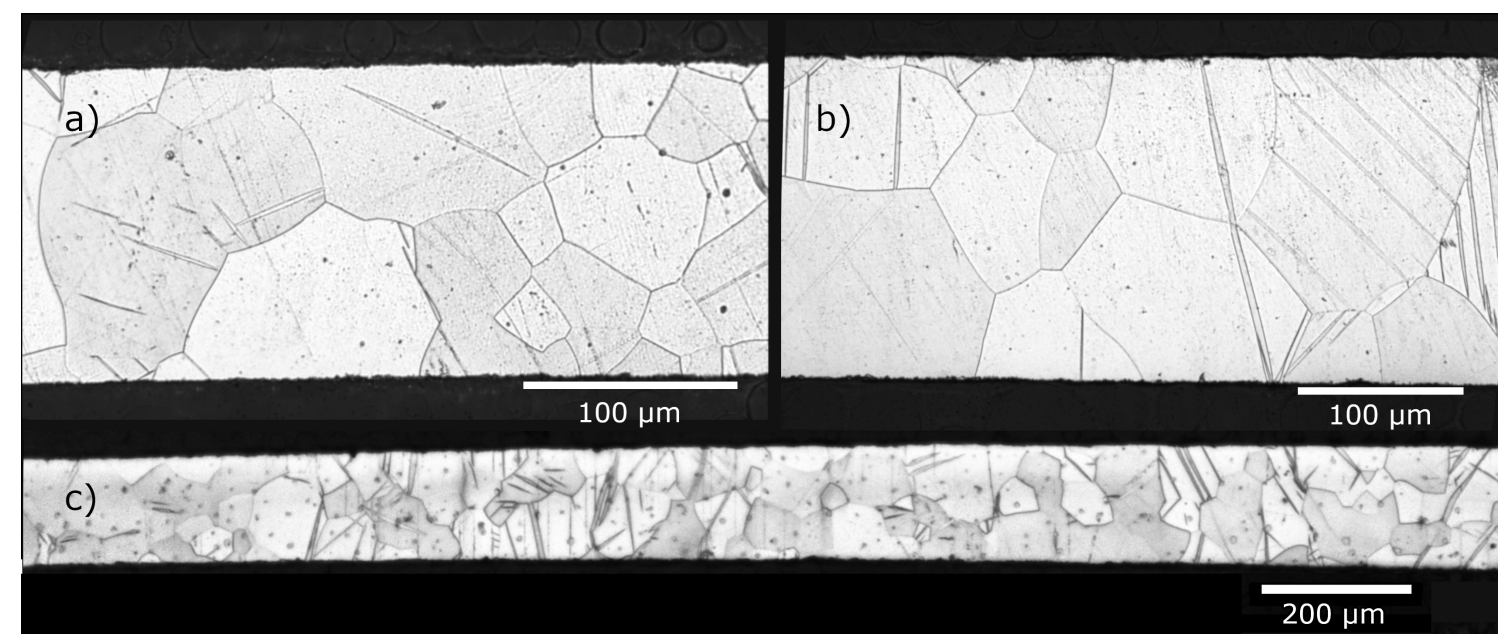

Figure 2. Micrographs of the annealed wire cross sections, (a) Mg-2Ag and (b) Mg-6Ag. A large number of twins is visible, which are introduced easily by bending especially in the annealed wires. (c) displays an overview of a larger part of the a $\mathrm{Mg}-2 \mathrm{Ag}$ wire for comparison.

Table 3. Grain size of wires determined by the linear intersect method.

\begin{tabular}{ccc}
\hline Alloy & Recrystallized & Solution Annealed \\
\hline Mg-2Ag & $10 \pm 1 \mu \mathrm{m}$ & $40 \pm 5 \mu \mathrm{m}$ \\
$\mathrm{Mg}-6 \mathrm{Ag}$ & $11 \pm 1 \mu \mathrm{m}$ & $61 \pm 10 \mu \mathrm{m}$ \\
\hline
\end{tabular}

\subsection{Degradation Analysis Based on NFHT}

Figure 3 shows an example of a slice of a tomographic reconstruction of a solution annealed $\mathrm{Mg}-2 \mathrm{Ag}$ wire after 7 days of degradation, as well as two 3D renderings of the same wire superimposed with a rendering of a non-degraded wire. The degradation layer can be distinguished from the residual metal of the wire within the tomographic reconstruction. However, image artefacts are visible that arise from phase wrapping due to the strong phase shift at the selected photon energies. The phase shift is induced by the wire and in particular material clusters therein, which are expected to be Ag precipitates.
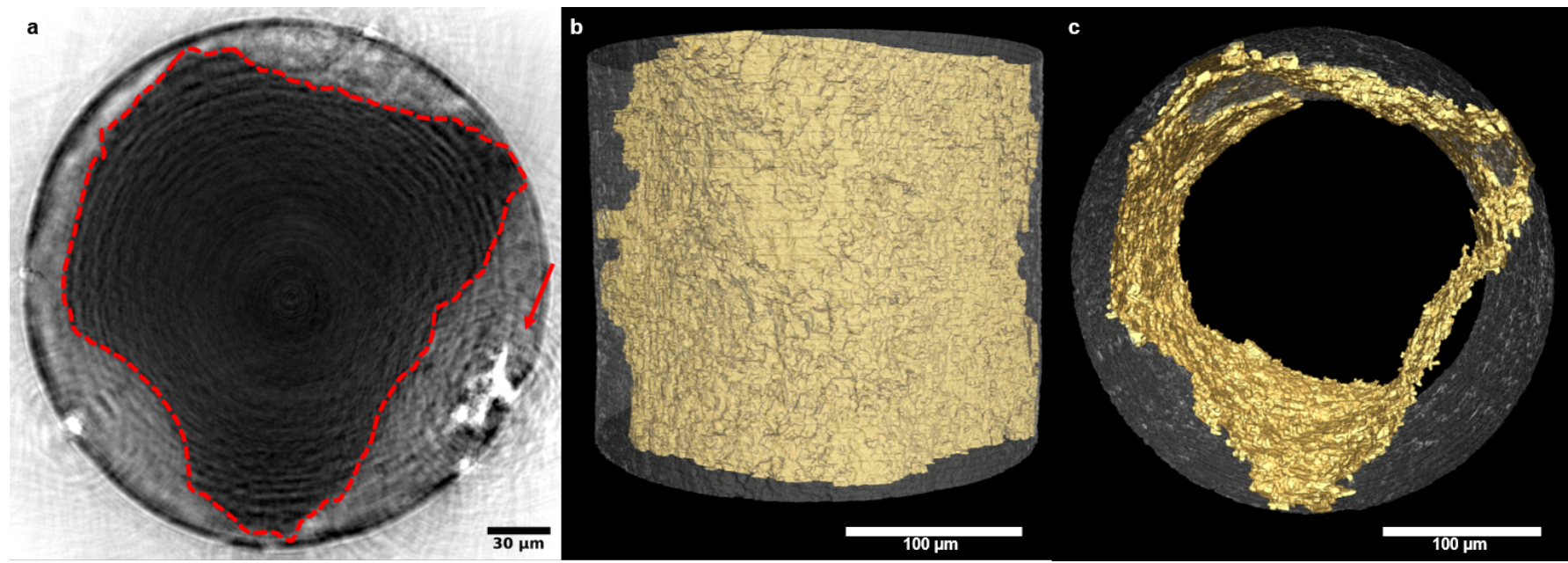

Figure 3. (a) Slice through tomographic reconstruction of a solution annealed $\mathrm{Mg}-2 \mathrm{Ag}$ wire after 7 days of degradation. The degradation layer can clearly be distinguished from the residual metal (dashed red outline). The red arrow indicates a cluster of strongly phase shifting materials within the sample, potentially Ag precipitates, and resulting phase wrapping artefacts. $(\mathbf{b}, \mathbf{c})$ The 3D surface rendering of the residual metal of the degraded wire shown in (a) obtained after segmentation and superimposed with a semi-transparent surface rendering of a non-degraded wire in two orthogonal directions. 
Figure 4 displays the degradation rate and pitting factor (mean \pm standard deviation) for both alloys before and after solution annealing at all time points of degradation as determined using NFHT. The standard deviation of both parameters is large for all settings, making only a comparison of trends possible. For 1 day of immersion only one sample was measured; therefore, no standard deviation is shown. It appears that $\mathrm{Mg}-2 \mathrm{Ag}$ degrades faster than $\mathrm{Mg}-6 \mathrm{Ag}$ after 7 days both before and after solution annealing. Solution annealing has decreased the degradation rate for both alloys after 7 days. After three days this trend is not yet visible and there are no apparent differences between the alloys and the treatments. For recrystallized Mg-6Ag wires the data suggests an initial increase in degradation rate after one day, followed by a decrease over time. The pitting factor appears to decrease over time and higher Ag content leads to a higher pitting factor. Similarly, the solution annealing also tends to increases the pitting factor, although a clear correlation cannot be established due to the high standard deviation. The degradation rate and pitting factor of $\mathrm{Mg}-6 \mathrm{Ag}$ in the recrystallized state after three days is negative for one wire $(-0.05 \mathrm{~mm} / \mathrm{yr}$ and -33.6 , respectively), as the mean radius of the degraded wire was larger than the mean radius of the non-degraded wires. This may be due to variances in the manufacturing process of the wire and very little degradation. In contrast, another recrystallized wire $\mathrm{Mg}$-6Ag displays a very high pitting factor (68.9) after 3 days of degradation, thus leading to a very high variation in the values of pitting factor. The largest pitting factor (421.4) was observed for a solution annealed $\mathrm{Mg}-6 \mathrm{Ag}$ wire after 3 days of degradation. This was due to a very localized corrosion pit and overall little to no degradation. Figure A1 shows exemplary heat maps of the different degradation depths of the three mentioned outliers and a fourth wire with high degradation rate for visual support. To determine the degradation inhomogeneity within one sample, Figure A2 shows the degradation rate and pitting factor calculated from the one sample per alloy and treatment imaged at three height steps after 7 days of immersion. The numbers differ little from the numbers presented in Figure 4, showing that both inter-sample and intra-sample variability are high.
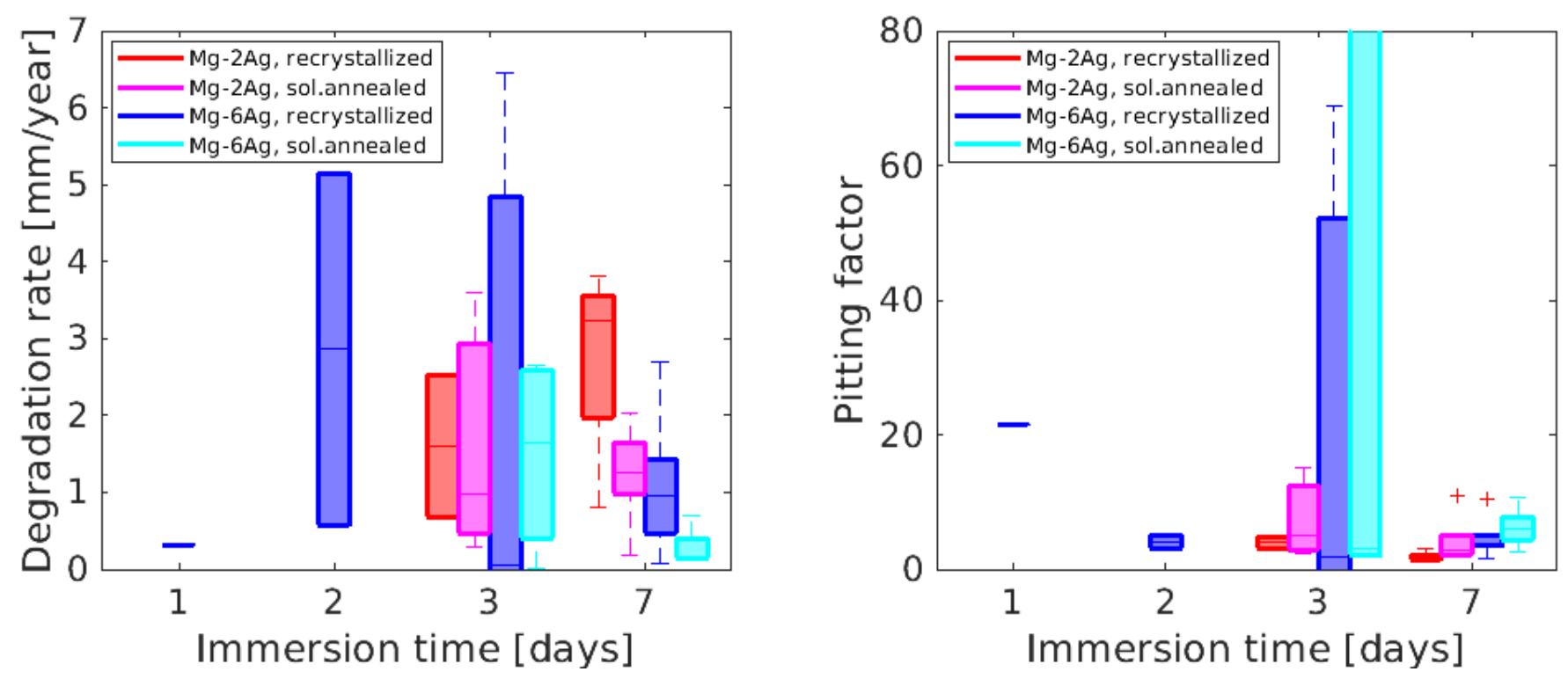

Figure 4. Degradation rate and pitting factor of $\mathrm{Mg}-2 \mathrm{Ag}$ and $\mathrm{Mg}-6 \mathrm{Ag}$ wires depending on the immersion time and treatment displayed as boxplots. The boxplots show the median of the parameters as a line and the 25th and 75th percentiles. Outliers are plotted as + . 
The observed trends are in part contrary to the results presented in the literature, which showed that higher Ag content leads to an increase in the degradation rate $[9,12,14]$. However, in agreement with previous studies, we have found that solution annealing lowers the degradation rate $[9,14]$. Differences in the degradation behaviour may be due to differences in the microstructure, as grain sizes in the recrystallized wires were similar for both $\mathrm{Mg}-2 \mathrm{Ag}$ and $\mathrm{Mg}-6 \mathrm{Ag}$, while as-cast material used in the studies by Tie et al. showed greater grain sizes of 350 to $600 \mu \mathrm{m}$, respectively, [12,14]. Moreover, Tie et al. utilized electrochemical corrosion resistance measurements for their analysis, which can only provide immediate measurements but fails to provide information on the longer term material behaviour. In agreement with the study by Estrin et al. [15], in which Mg-2Ag and $\mathrm{Mg}-4 \mathrm{Ag}$ after T4 treatment and following equal-channel angular pressing (ECAP) were studied, we find that at early time points ( 2 or 3 days) the degradation rate of the different alloys after heat treatment do not differ significantly. At the same time, ECAP, which reduces the grain size and increases the number of $\mathrm{Mg}_{4} \mathrm{Ag}$ precipitates, similar to the recrystallized state in this study, leads to higher degradation rates in $\mathrm{Mg}-4 \mathrm{Ag}$ than $\mathrm{Mg}-2 \mathrm{Ag}$, which is in agreement with the trends observed here. After 7 days of immersion, the ECAP treated alloys had similar degradation rates, which agrees with the recrystallized wires in this study, while the T4 treated Mg-2Ag wires had lower degradation rates than $\mathrm{Mg}-4 \mathrm{Ag}$, which is in contrast to results found here. In agreement with the Liu et al. [9] we find that higher Ag content appears to lead to a higher tendency for pitting corrosion after heat treatment.

Figure 5 shows the correlation between degradation rate and pitting factor, combined for all time points, with the inset displaying the results after removal of outliers. Larger pitting factors can be associated with lower degradation rates, while the lowest pitting factors are associated with larger degradation rates. $\mathrm{Mg}-6 \mathrm{Ag}$ in the recrystallized state shows the highest variation across both scales, while a lower amount of Ag and the solution annealing are limiting the variability of the parameters. This shows that in particular for $\mathrm{Mg}$ wires with a higher content of $\mathrm{Ag}$, the solution annealing is a crucial processing step to control the degradation rate and degradation homogeneity.

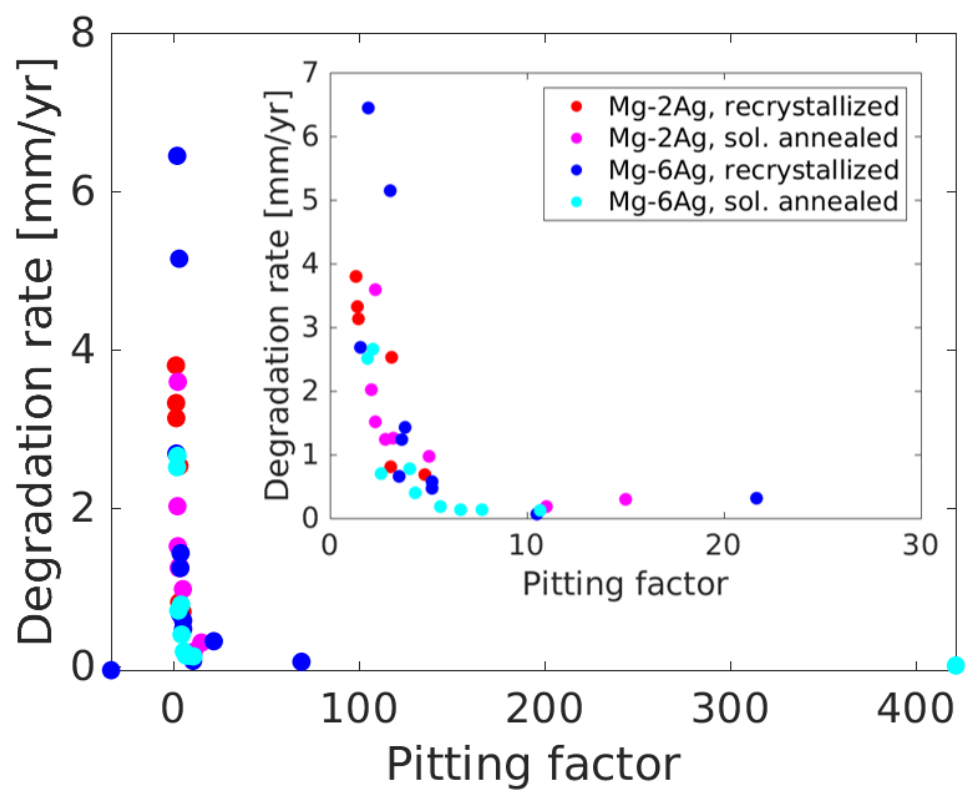

Figure 5. Correlation between degradation rate and pitting factor for all alloys and treatments at all time points. The inset displays the correlation after removal of the outliers. 
The results show that NFHT is a useful method in analysing the degradation rate of thin $\mathrm{Mg}$ alloy wires, whose degradation at early time points could otherwise not be assessed. However, due to the relatively small FOV, several areas per sample and larger sample numbers need to be investigated to achieve lower variations in the degradation parameters in the future. Nevertheless, as shown in Figure A2, even the degradation inhomogeneity within one sample is high. Due to the long imaging times required for NFHT it may therefore be beneficial to utilize TXM in the future, which enables imaging within 15 minutes per tomogram [29], if sufficiently large FOVs or sufficiently small wire diameters can be achieved, respectively.

\title{
4. Conclusions
}

We have shown that X-ray near-field holotomography is a suitable method to study the degradation of $\mathrm{Mg}$ alloy wires with a field of view tailored to the wire size and submicrometer resolution. Overall, 40 wires were imaged, processed, and analysed for this study. The results of the study suggest that $\mathrm{Mg}-6 \mathrm{Ag}$ may be an interesting candidate for the use as an implant material due to a lower degradation rate after 7 days in combination with the potential for higher Ag release into the biological system.

Author Contributions: Conceptualization, B.Z.-P. and B.W.; methodology, B.Z.-P., J.H., and B.W.; formal analysis, A.W., S.M., K.I., and B.Z.-P.; material production, D.S. and S.M.; investigation, S.M., S.B., D.S., H.C.., J.H., S.F., I.G., and B.Z.-P.; writing—original draft preparation, B.Z.-P., S.M., and B.W.; writing—review and editing, all authors; visualization, B.Z.-P. and S.M.; supervision, B.Z.-P., B.W., and R.W.-R. All authors have read and agreed to the published version of the manuscript.

Funding: The authors H.Ć. and K.I. acknowledge funding from the European Union's Horizon 2020 research and innovation program under the Marie Skłodowska-Curie grant, agreement No 811226. The author D.S. acknowledges funding from the German Research Foundation (DFG, project number 404534760).

Institutional Review Board Statement: Not applicable.

Informed Consent Statement: Not applicable.

Data Availability Statement: Due to the size of the X-ray near-field holotomography datasets, all data is available only upon request to the corresponding authors.

Acknowledgments: We acknowledge provision of beamtime related to the proposal I-20191320 at the nanotomography end-station of beamline P05 at PETRA III at DESY, a member of the Helmholtz Association (HGF). This research was supported in part through the Maxwell computational resources operated at DESY.

Conflicts of Interest: The authors declare no conflict of interest. The funders had no role in the design of the study; in the collection, analyses, or interpretation of data; in the writing of the manuscript, or in the decision to publish the results.

\author{
Abbreviations \\ The following abbreviations are used in this manuscript: \\ SEM Scanning electron microscopy \\ BSE Back-scattering electron \\ TXM Transmission X-ray microscopy \\ NFHT Near-field holotomography \\ FOV Field-of-view \\ OSA Order sorting aperture
}




\section{Appendix A. Supplementary Figures}
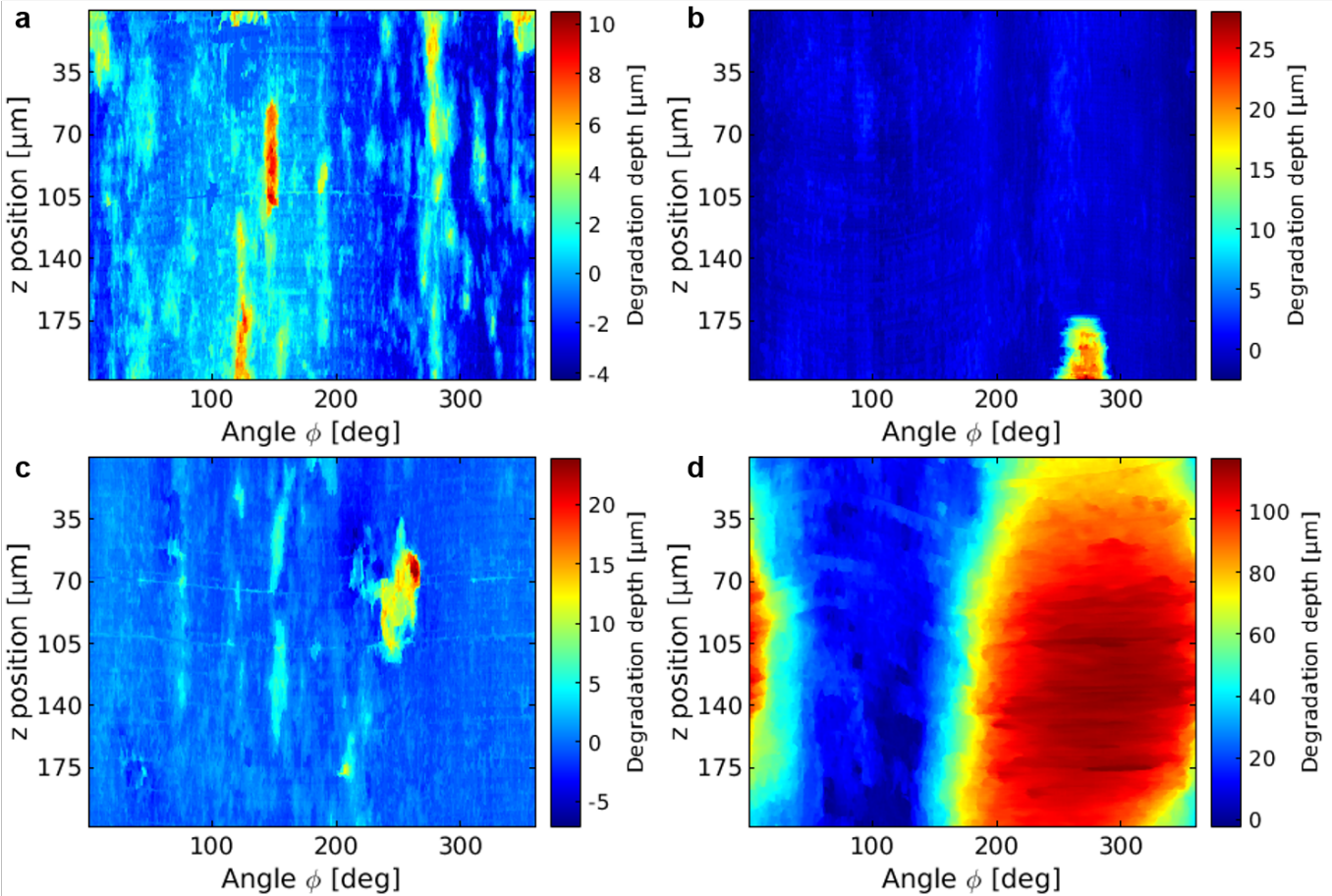

Figure A1. Exemplary heat maps of the localised degradation depth of four wires following radial reslicing. (a) displays the recrystallized $\mathrm{Mg}-6 \mathrm{Ag}$ wire after 3 days of immersion, which resulted in a negative degradation rate and pitting factor $(-0.05 \mathrm{~mm} / \mathrm{yr}$ and -33.6 , respectively). (b) shows the wire with the highest pitting factor of 421.4, which was found for a solution annealed $\mathrm{Mg}-6 \mathrm{Ag}$ wire after 3 days of immersion, due to the low overall degradation. (c) displays a recrystallized $\mathrm{Mg}-6 \mathrm{Ag}$ wire after 3 days of immersion with low degradation rate $(0.06 \mathrm{~mm} / \mathrm{yr})$ and high pitting factor (68.9). (d) shows a recrystallized $\mathrm{Mg}-6 \mathrm{Ag}$ wire after 3 days of immersion with high degradation rate $(6.45 \mathrm{~mm} / \mathrm{yr})$ and lower pitting factor (1.9.)
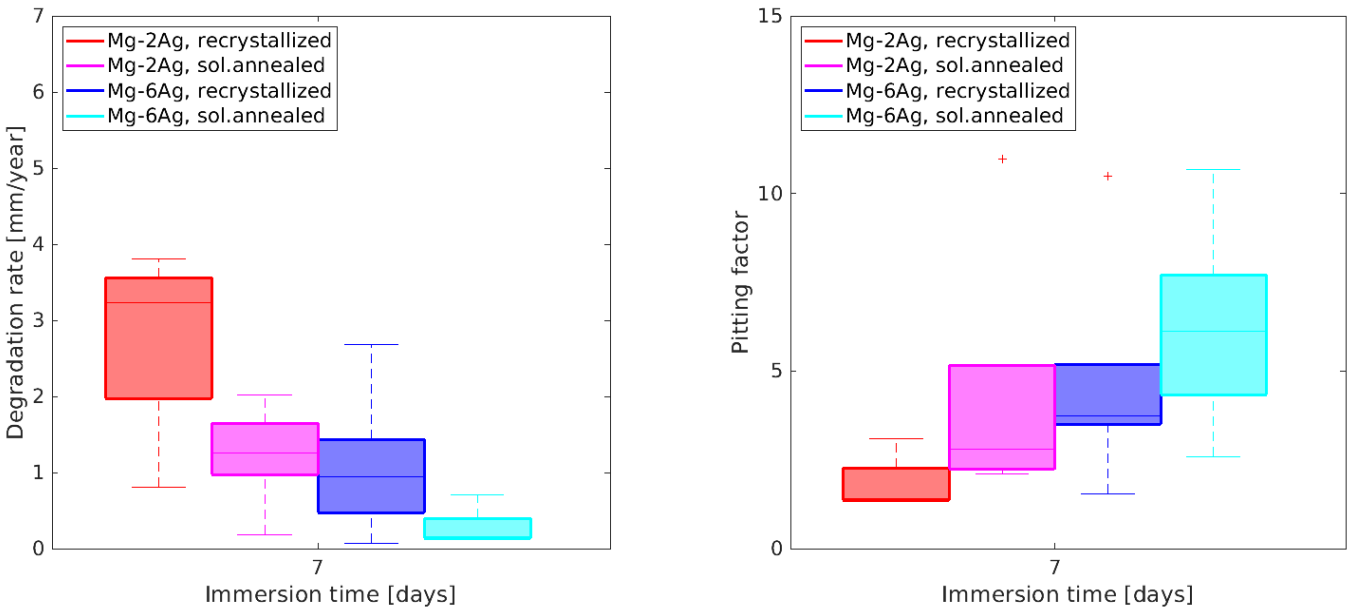

Figure A2. Degradation rate and pitting factor of the one recrystallized and solution annealed $\mathrm{Mg}$ 2Ag and $\mathrm{Mg}-6 \mathrm{Ag}$ wire each after 7 days of immersion evaluated at three different heights displayed as boxplots. The boxplots show the median of the parameters as a line and the 25 th and 75 th percentiles. Outliers are plotted as + . 


\section{References}

1. Witte, F. The history of biodegradable magnesium implants: A review. Acta Biomater. 2010, 6, 1680-1692. [CrossRef]

2. Seitz, J.M.; Lucas, A.; Kirschner, M. Magnesium-Based Compression Screws: A Novelty in the Clinical Use of Implants. JOM 2016, 68, 1177-1182. [CrossRef]

3. Bennett, J.; Hemptinne, Q.D.; McCutcheon, K. Magmaris resorbable magnesium scaffold for the treatment of coronary heart disease: overview of its safety and efficacy. Expert Rev. Med. Devices 2019, 16, 757-769. [CrossRef] [PubMed]

4. Huse, E.C. A New Ligature? Chic. Med. J. Exam. 1878, 38, 171-172.

5. Seitz, J.M.; Utermöhlen, D.; Wulf, E.; Klose, C.; Bach, F.W. The Manufacture of Resorbable Suture Material from MagnesiumDrawing and Stranding of Thin Wires. Adv. Eng. Mater. 2011, 13, 1087-1095. [CrossRef]

6. Rostock, P. Ist das Magnesium als Naht- und Sehienungsmaterialfiir Knochenoperationen geeignet? Arch. Orthop. Unf.-Chir. 1937, 38, 486-492. [CrossRef]

7. Alaneme, K.; Okotete, E. Enhancing plastic deformability of $\mathrm{Mg}$ and its alloys-A review of traditional and nascent developments. J. Magnes. Alloy. 2017, 5, 460-475. [CrossRef]

8. Wiese, B.; Willumeit-Römer, R.; Letzig, D.; Bohlen, J. Alloying effect of silver in magnesium on the development of microstructure and mechanical properties by indirect extrusion. J. Magnes. Alloy. 2021, 9, 112-122. [CrossRef]

9. Liu, Z.; Schade, R.; Luthringer, B.; Hort, N.; Rothe, H.; Müller, S.; Liefeith, K.; Willumeit-Römer, R.; Feyerabend, F. Influence of the Microstructure and Silver Content on Degradation, Cytocompatibility, and Antibacterial Properties of Magnesium-Silver Alloys in Vitro. Oxidative Med. Cell. Longev. 2017, 2017. [CrossRef] [PubMed]

10. Nienaber, M.; Yi, S.; Kainer, K.U.; Letzig, D.; Bohlen, J. On the Direct Extrusion of Magnesium Wires from Mg-Al-Zn Series Alloys. Metals 2020, 10, 1208. [CrossRef]

11. Kustra, P.; Milenin, A.; Byrska-Wójcik, D.; Grydin, O.; Schaper, M. The process of ultra-fine wire drawing for magnesium alloy with the guaranteed restoration of ductility between passes. J. Mater. Process. Technol. 2017, 247, 234-242. [CrossRef]

12. Tie, D.; Feyerabend, F.; Hort, N.; Hoeche, D.; Kainer, K.; Willumeit, R.; Mueller, W. In vitro mechanical and corrosion properties of biodegradable Mg-Ag alloys. Mater. Corros. 2014, 65, 569-576. [CrossRef]

13. Liu, Z.; Feyerabend, F.; Bohlen, J.; Willumeit-Römer, R.; Letzig, D. Mechanical properties and degradation behavior of binary magnesium-silver alloy sheets. J. Phys. Chem. Solids 2019, 133, 142-150. [CrossRef]

14. Tie, D.; Feyerabend, F.; Müller, W.D.; Schade, R.; Liefeith, K.; Kainer, K.; Willumeit, R. Antibacterial biodegradable Mg-Ag alloys. Eur. Cells Mater. 2013, 25, 284-298. [CrossRef] [PubMed]

15. Estrin, Y.; Martynenko, N.; Anisimova, N.; Temralieva, D.; Kiselevskiy, M.; Serebryany, V.; Raab, G.; Straumal, B.; Wiese, B.; Willumeit-Römer, R.; et al. The effect of equal-channel angular pressing on the microstructure, the mechanical and corrosion properties and the anti-tumor activity of magnesium alloyed with silver. Materials 2019, 12, 3832. [CrossRef]

16. Gonzalez, J.; Hou, R.Q.; Nidadavolu, E.P.S.; Willumeit-Römer, R.; Feyerabend, F. Magnesium degradation under physiological conditions-Best practice. Bioact. Mater. 2018, 3, 174-185. [CrossRef]

17. van Gaalen, K.; Gremse, F.; Benn, F.; McHugh, P.E.; Kopp, A.; Vaughan, T.J. Automated ex-situ detection of pitting corrosion and its effect on the mechanical integrity of rare earth magnesium alloy-WE43. Bioact. Mater. 2021. [CrossRef]

18. Zeller-Plumhoff, B.; Tolnai, D.; Wolff, M.; Greving, I.; Hort, N.; Willumeit-Römer, R. Utilizing Synchrotron Radiation for the Characterization of Biodegradable Magnesium Alloys-From Alloy Development to the Application as Implant Material. Adv. Eng. Mater. 2021, 2100197. [CrossRef]

19. Zeller-Plumhoff, B.; Helmholz, H.; Feyerabend, F.; Dose, T.; Wilde, F.; Hipp, A.; Beckmann, F.; Willumeit-Römer, R.; Hammel, J.U. Quantitative characterization of degradation processes in situ by means of a bioreactor coupled flow chamber under physiological conditions using time-lapse SR $\mu$ CT. Mater. Corros. 2018, 69, 298-306. [CrossRef]

20. Zeller-Plumhoff, B.; Laipple, D.; Slominska, H.; Iskhakova, K.; Longo, E.; Hermann, A.; Flenner, S.; Greving, I.; Storm, M.; Willumeit-Römer, R. Evaluating the morphology of the degradation layer of pure magnesium via 3D imaging at resolutions below $40 \mathrm{~nm}$. Bioact. Mater. 2021, 6, 4368-4376. [CrossRef]

21. Bartels, M.; Krenkel, M.; Haber, J.; Wilke, R.N.; Salditt, T. X-ray holographic imaging of hydrated biological cells in solution. Phys. Rev. Lett. 2015, 114, 48103. [CrossRef] [PubMed]

22. Cloetens, P.; Ludwig, W.; Baruchel, J.; Van Dyck, D.; Van Landuyt, J.; Guigay, J.P.; Schlenker, M. Holotomography: Quantitative phase tomography with micrometer resolution using hard synchrotron radiation x rays. Appl. Phys. Lett. 1999, 75, $2912-2914$. [CrossRef]

23. Kree, V.; Bohlen, J.; Letzig, D.; Kainer, K. The metallographical examination of magnesium alloys [Metallographische Gefügeuntersuchungen von Magnesiumlegierungen]. Prakt. Metallogr./Pract. Metallogr. 2004, 41, 233-246.

24. Flenner, S.; Kubec, A.; David, C.; Storm, M.; Schaber, C.F.; Vollrath, F.; Müller, M.; Greving, I.; Hagemann, J. Hard X-ray nano-holotomography with a Fresnel zone plate. Opt. Express 2020, 28, 37514-37525. [CrossRef] [PubMed]

25. Hagemann, J.; Töpperwien, M.; Salditt, T. Phase retrieval for near-field X-ray imaging beyond linearisation or compact support. Appl. Phys. Lett. 2018, 113, 041109. [CrossRef]

26. Gürsoy, D.; De Carlo, F.; Xiao, X.; Jacobsen, C. TomoPy: A framework for the analysis of synchrotron tomographic data. Proc. Spie Int. Soc. Opt. Eng. 2014, 9212. [CrossRef]

27. Schindelin, J.; Arganda-Carreras, I.; Frise, E.; Kaynig, V.; Longair, M.; Pietzsch, T.; Preibisch, S.; Rueden, C.; Saalfeld, S.; Schmid, B.; et al. Fiji: an open-source platform for biological-image analysis. Nat. Methods 2012, 9, 676-682. [CrossRef] 
28. Bian, M.; Huang, X.; Chino, Y. Microstructures and Mechanical Properties of Precipitation-Hardenable Magnesium-Silver-Calcium Alloy Sheets. Metals 2020, 10, 1632. [CrossRef]

29. Flenner, S.; Storm, M.; Kubec, A.; Longo, E.; Döring, F.; Pelt, D.M.; David, C.; Müller, M.; Greving, I. Pushing the temporal resolution in absorption and Zernike phase contrast nanotomography: enabling fast in situ experiments. J. Synchrotron Radiat. 2020, 27, 1339-1346. [CrossRef] 